\title{
Teenage pregnancy: trends, contributing factors and the physician's role
}

\section{Donald B. Langille}

$\mathrm{T}$ eenage pregnancy is an important public health issue: it is common, largely preventable and associated with negative sequelae, both for the teenagers who become pregnant and for their children. Compared with babies of older mothers, those born to teenagers are more likely to have lower birth weights, increased infant mortality, an increased risk of hospital admission in early childhood, ${ }^{1}$ less supportive home environments, poorer cognitive development and, if female, a higher risk of becoming pregnant themselves as teenagers. ${ }^{2}$ Teenaged mothers more often than other teenagers are socially isolated, have mental health problems,${ }^{1}$ and have fewer educational and employment opportunities. ${ }^{3}$ The evidence used to support these associations, however, has often failed to consider that teenaged mothers may have characteristics (e.g., coming from lowincome households) that lead to disadvantaged life trajectories regardless of whether they are pregnant. ${ }^{2}$

Rates of teenage pregnancy vary by country, but because of reporting differences, international comparisons can be difficult. In 2002, the latest year for which international data are available for comparison, Canada had a pregnancy rate of 33.9 per 1000 females aged $15-19,{ }^{4}$ much lower than the rate that year in England and Wales ${ }^{5}$ and the United States ${ }^{6}$ (Table I). From 1994 to 2002, the rate of teenage pregnancy declined substantially in both Canada and the United States, ${ }^{4,6}$ but it increased slightly in England and Wales ${ }^{5}$ (Table I). In 2002 the rate of therapeutic abortion in Canada was I8.4 per Iooo females aged $15-19,{ }^{4}$ again lower than the rates in England and Wales ${ }^{5}$ and the United States, ${ }^{6}$ but not substantially so (Table I). One can conclude, therefore, that Canadian teenagers become pregnant less often than those in England and Wales and the United States but more often choose to terminate the pregnancy.

Reasons for the decline in teenage pregnancy in the United States were examined in a study using data from the National Survey of Family Growth in the years 1995 and 2002. The pro-

Table 1: Rates of pregnancy and abortion per 1000 females aged 15-19 years in Canada, England and Wales, and the United States

\begin{tabular}{lcccc}
\hline & \multicolumn{2}{c}{$\begin{array}{c}\text { Pregnancy rate } \\
\text { per } 1000\end{array}$} & & $\begin{array}{c}\text { Abortion rate } \\
\text { per } 1000\end{array}$ \\
\cline { 2 - 3 } \cline { 5 - 5 } Country & 1994 & 2002 & & 2002 \\
\hline Canada & 49.2 & 33.9 & & 18.4 \\
England and Wales & 58.7 & 60.3 & & 24.1 \\
United States & 106.1 & 76.4 & & 21.7 \\
\hline
\end{tabular}

Box 1: Key messages for physicians who provide clinical services to teenagers

- Many teenagers are sexually active, sometimes at quite early ages

- Teenagers may not spontaneously raise questions about their sexual health concerns. Be proactive: ask all teenaged patients about sexual activity, use of contraception and need for information about other sexual health issues

- Prepared "scripts" can be helpful when talking to teenagers about sexual health

- Contraception should be provided when indicated

- Abortion counselling and referral should be provided when needed

- Many adolescents have the emotional and cognitive maturity to receive confidential sexual health services, but many are not aware that they are entitled to patient confidentiality

- If pregnant teenagers choose to continue to term, exemplary care should be provided before, during and after delivery

portion of females aged I5-19 who reported using an oral contraceptive at last intercourse, alone or in combination with other methods, increased dramatically during this period, from $32 \%$ to $49 \%$. The proportion who reported using an injectable long-acting hormonal contraceptive (e.g., DepoProvera) also increased, from $8 \%$ to $10 \%$. Reports of using no contraception at last intercourse decreased, from $34 \%$ to $18 \%$ of respondents. The authors concluded that improved contraceptive use was the main factor behind decreased rates of teenage pregnancy in the United States; it explained all variability in pregnancy risk among respondents aged I8-I9, although decreased sexual activity played a minor role among those aged $15-17 .^{7}$ Similar studies have not been conducted in Canada; however, data from a national survey in 2002 suggest that contraceptive use also plays an important role here. In that survey, $39 \%$ of Canadian females in grade 9 and $54 \%$ in grade II reported using oral contraception at last intercourse; $8 \%$ and $6 \%$ respectively reported using no contraception, and $7 \%$ and $11 \%$ reported using the withdrawal method, either alone or in combination with other methods. ${ }^{8}$

Teenagers' choices to become sexually active and to use contraception, as well as their ability to obtain and use contraception if this choice is made, are influenced by many factors. These factors operate at the individual level (e.g., knowledge, attitudes and beliefs, future expectations, substance use), the intrafamilial level (e.g., family structure, parent- 
child communication, socioeconomic status), the extrafamilial level (e.g., peer influences, sexual health education at school, health services) and the community level (e.g., norms and values concerning teenage pregnancy). Some of these factors are readily modifiable, such as individual knowledge about sexual health, but others are not easily changed or cannot be changed at all.

Although physician groups can lobby for policy initiatives aimed at changing sexual risk behaviours among teenagers, including enhanced sexual education at schools, the most important role for physicians is to provide appropriate sexual health information and services in their practices if they are providing clinical services to youths (Box I). Physicians must recognize the reality of teenage sexual activity. Studies have shown that, by the end of high school, the majority of teenagers have had sexual intercourse $e^{9,10}$ and that about 10\% have had intercourse before age $15 .^{9,11}$ As part of the general enquiry into their wellbeing, physicians should ask all teenagers about their sexual activity, use of condoms and contraception, history of sexually transmitted infections and pregnancy, and the need for information about other sexual health concerns. Discussions about sexual health issues may not always be initiated by the adolescent, for whom the process of seeking sexual health advice is a complicated one, and therefore physicians must be proactive in making such an enquiry. Scripts for these discussions may be helpful; a useful approach is outlined in the 2006 Canadian Guidelines on Sexually Transmitted Infections. ${ }^{12}$

When contraception, including emergency contraception, is indicated for teenagers, it should be provided. Like other women, adolescents also have a right to abortion services, although the availability of such services is not uniform across the country, and teenaged girls of low socioeconomic status or from visible minorities have particularly limited access. ${ }^{13}$ Teenagers have the right to confidential health care, including receiving sexual health services, provided their emotional and cognitive maturity allow for this. Their parents do not have an automatic right to know. The right to confidentiality is not always understood by teenagers and should be appropriately communicated during patient encounters. Finally, when teenagers choose to continue their pregnancy to term, exemplary care should be provided before, during and after delivery, to help minimize the risk of negative outcomes that may occur.

This article has been peer reviewed.

Donald Langille is with the Department of Community Health and Epidemiology, Faculty of Medicine, Dalhousie University, Halifax, NS.

Competing interests: None declared.

\section{REFERENCES}

I. Botting B, Rosato M, Wood R. Teenage mothers and the health of their children. Popul Trends I998;93:19-28.

2. Wellings $\mathrm{K}$, Wadsworth J, Johnson A, et al. Teenage fertility and life chances. Rev Reprod I999;4:184-90.

3. Corcoran J. Consequences of adolescent pregnancy/parenting: a review of the literature. Soc Work Health Care 1998;27:49-67.

4. Pregnancy outcomes, by age group, Canada, provinces and territories, annual [Table Io6-9002]. Ottawa: Statistics Canada. Available: http://cansim2.statcan.ca /cgi-win/cnsmcgi.exe?Lang=E\&RootDir=CII/\&ResultTemplate=CII/CII_\&Array Pick=I\&ArrayId=I069002 (accessed 2007 Apr 2).

5. Office for National Statistics. Conceptions statistics: conceptions for women resident in England and Wales, 2004. Supplement to Series FMr no 34. London (UK): The Office; 2006. Available: www.statistics.gov.uk/downloads/theme_population /FMI_34/FMI_Conc_Sup_2004.pdf (accessed 2007 Apr. 2).

6. National Center for Health Statistics, US Centers for Disease Control and Prevention. Recent trends in teenage pregnancy in the United States, I990-2002. Hyattsville (MD): National Center for Health Statistics. Available: www.cdc.gov/nchs /products/pubs/pubd/hestats/teenpregi990-2002/teenpregi990-2002.htm (accessed 2007 Apr 3).

7. Santelli JS, Duberstein Lindberg L, Finer LB, et al. Explaining recent declines in adolescent pregnancy in the United States: the contribution of abstinence and improved contraceptive use. Am J Public Health 2007;97:150-6.

8. Boyce W, Doherty-Poirier M, MacKinnon D, et al. Sexual health of Canadian youth findings from the Canadian Sexual Health and HIV/AIDS Study. Can J Hum Sex 2006; $15: 59-68$.

9. Maticka-Tyndale E. Sexual health and Canadian youth: How do we measure up? Can J Hum Sex 200I; I0:I-I7.

Io. Poulin C. Nova Scotia student drug use 2002: technical report. Halifax: Nova Scotia Department of Health and Dalhousie University; 2002. Available: www.gov.ns.ca /health/downloads/2002_NSDrugTechnical.pdf (accessed 2007 Apr I9).

II. Langille DB, Hughes J, Murphy GT, et al. Socio-economic factors and adolescent sexual activity and behaviour in Nova Scotia. Can J Public Health 2005;96:313-8.

I2. Public Health Agency of Canada. Canadian guidelines on sexually transmitted infections: 2006 edition. Ottawa: The Agency; 2006. p. I9. Available: www.phac-aspc.gc .ca/std-mts/sti_2006/pdf/sti2006_e.pdf (accessed 2007 Apr 3).

I3. Rodgers S, Downie J. Abortion: ensuring access [editorial]. CMAJ 2006;175:9.

Correspondence to: Dr. Donald B. Langille, Department of Community Health and Epidemiology, Faculty of Medicine, Dalhousie University, 5790 University Ave., Halifax NS $\mathrm{B}_{3} \mathrm{H}_{\mathrm{I}} \mathrm{V7}$; donald.langille@dal.ca 